\title{
A Cohort Study on the Effectiveness of Ethics Education in Engineering \& Engineering Technology Programs
}

\section{Prof. Jason K. Durfee, Eastern Washington University}

Jason Durfee is a Professor of Engineering \& Design at Eastern Washington University. He received his BS and MS degrees in Mechanical Engineering from Brigham Young University. He holds a Professional Engineer certification. Prior to teaching at Eastern Washington University, he was a military pilot, an engineering instructor at West Point and an airline pilot. His interests include aerospace, aviation, computational fluid dynamics, professional ethics, and piano technology.

\section{Dr. Hani Serhal Saad, Eastern Washington University}

B.S. and M.S. in Mechanical Engineering, Marquette University PhD. in Mechanical Engineering, Washington State University 


\title{
A Cohort Study on the Effectiveness of Ethics Education in Engineering \& Engineering Technology Programs
}

\begin{abstract}
A few years ago our university underwent a major overhaul of the manner in which professional ethics was taught in our engineering and engineering technology programs. One change was to ensure that ethics topics were included in all core courses. Another change involved the addition of an ethics module to a history of technology course taken by all students in our programs. A course that specifically covered engineering ethics was already part of the curriculum. The ethics coverage in our senior capstone course was also improved and this included the use of an ethics examination available on the website of the National Society of Professional Engineers (NSPE). The NSPE exam was used as an assessment tool as well as a source for further discussion on professional ethics. Soon after these changes were implemented a cohort study was begun in order to assess the effectiveness of these changes. Knowledge of professional ethics was assessed in a freshman course taken by engineering and engineering technology students. Later, when these students were in their senior capstone course they were assessed again and the results were compared. This paper describes the process used in the cohort study as well as the results derived from that study. Data from the study did not show a significant increase in the scores on the NSPE ethics exam used for assessment from freshman to senior years. The conclusion could be that either this exam is not an effective assessment tool or that students did not significantly increase their knowledge of professional ethics from the educational methods that were used during the study.
\end{abstract}

\section{Introduction}

We expend great effort into preparing engineering and engineering technology students to deal with the technical problems they will encounter in their future careers but we don't always adequately address the ethical problems that they might have to deal with. Working engineers generally understand the importance of professional ethics. Instructors and professors in college engineering programs understand the importance of professional ethics. Unfortunately not all students in engineering programs understand the importance professional ethics in their future careers. Many do not even know for sure what the term 'professional ethics' really entails. The topic is not the easiest to teach to engineering students who are very math oriented. Many standards and codes have been established including one by the NSPE${ }^{1}$ and Tau Beta $\mathrm{Pi}^{2}$. Research has shown ${ }^{3}$ that proper engagement with the students might make them more interested in the topic. This can be done effectively by examining past cases ${ }^{4}$ as well as future ones that will result from new products not yet released to society. Unlike the former approach, the latter, referred to as the Social Impact Approach is particularly beneficial in forcing the students to 
think about the ethical problems related to products that exist but are not yet available. This removes the hind sight perspective present when examining past cases.

From a practical viewpoint, a basic knowledge of professional ethics is required in order to pass the examinations required for licensure. Also, the Accrediting Board for Engineering and Technology (ABET) recognizes the importance of professional ethics and requires that this topic be addressed in undergraduate education in order to maintain ABET accreditation ${ }^{6}$. This paper looks into our institution's approach to professional ethics education in regards to an accreditation visit that occurred a few years ago.

Results from an accreditation visit to our institution to review our Mechanical Engineering Technology (MET) program revealed that we needed to increase our coverage of topics in professional ethics. An inter-curricular approach was created to infuse the program with professional ethics so that a student would encounter this topic throughout their time in school. Previous to this change there was little direction that instructors should address ethics in their courses, other than one specific required course that had the word, "ethics," in its title. Some elements of this new ethics program were discussed in a paper previously presented at the American Society of Engineering Education (ASEE) Annual Conference and Exposition. ${ }^{7}$

\section{Program Outline}

The first aspect of our new approach involved infusing professional ethics into each of the core engineering courses. Each course (i.e. fluid mechanics, thermodynamics, solid mechanics, etc.) would include at least one course-related lesson on the topic of professional ethics sometime during the quarter. The format of this was not directly specified thereby giving instructors the flexibility to decide how to best incorporate this topic into the course. Many instructors used a case study format to do this. Some decided to merely present ideas on professional ethics related to the students' future careers. Some required student homework related to this topic and others did not. The idea was that students would be continually exposed to the topic throughout their career.

A second aspect of this new approach to teaching professional ethics involved the creation of a specific professional ethics module that was included in a course required by all MET students. This course covers the concepts of how technology and society interact and also fulfills a general education requirement for students at our university. Consequently, the majority of students in the course are not MET majors and, in fact, many sections have a majority of students that are enrolled in non-STEM-related majors. This was a great opportunity to expose students outside of our department to the idea of professional ethics, but it also required that the topic be presented in a much broader, non-engineering specific manner.

A third aspect of our approach involved a review of the course materials used in a dedicated ethics course that is required in the program. This course is a 2-credit hour course (on a quarter basis) that covers three different engineering-related topics: ethics, contracts, and patents. 
The final part of our new approach involved modifications to our senior capstone course. Changes to this course included the creation of a student portfolio and a module on professional ethics. One important part of the student portfolio was a requirement that students create a future plan of where they would see themselves in 10 years. They then needed to research what types of skills/knowledge/certifications/courses they would need to get to this point in the future. Included in their assignment was the requirement to address how professional ethics directly tied in to their ability to achieve their goal. When this portfolio assignment is given to the students they are given a lesson on professional ethics. This lesson is geared toward these senior students who will be graduating soon and headed into the workforce. Since these students have now been through all aspects of the professional ethics education in our department it was assumed that they would be very conversant on the topic and should be able to adequately discuss this topic with the instructor.

At the time these changes were implemented, a study was begun to attempt to assess the effect of this new professional ethics education system.

\section{The Study}

At the time these changes in professional ethics education were being implemented it was decided that the NSPE Ethics Exam ${ }^{1}$ from the NSPE website would be used to assess how well students understood the topic. A copy of this examination is attached to the end of this paper. The NSPE website provides different options on how to take the exam. It can be taken directly on line and a score will be provided. Our use of the exam involved printing out the exam from the website and giving the students paper copies for their answers. The exam consists of 25 statements and the students are required to mark whether they think the statement is True or False. The corresponding section of the NSPE Code of Ethics that the statement addresses is indicated on the exam. An answer key is provided so you can score a paper version of the exam. Each exam statement can then be searched in the NSPE Code of Ethics to find the important aspect of ethics that the particular statement was assessing.

This exam is given to students in the senior capstone course. After students take the exam it is graded and used as a basis for further discussion. Year-to-year results allow the department to see the effects of implementing this new program for teaching professional ethics. All aspects of this new program were implemented at the same time so the complete effects of the program would not be visible in the senior capstone course for four or more years from implementation as the youngest freshmen finally begin their capstone experience. Tracking the capstone results would provide an indication of how the new program was changing student understanding of professional ethics.

In addition to the results from the capstone course, this same exam was administered in a 100level CAD course that is taken primarily by freshmen and sophomore students. This course teaches introductory engineering graphics to students majoring in Mechanical Engineering 
Technology, Computer Engineering Technology, Manufacturing Technology, and Construction Management Technology. The exam was given to the students and collected by the instructor. Data for the MET students was extracted so that comparison of results would be only for students in this program. No answers were provided to the students in this 100-level course and the corrected exam was not returned to them. This was done to provide a baseline on the level of professional ethics knowledge of the students as they began their MET program. This would be compared with the scores from the senior capstone to see how they compared.

The study took place over the course of 5 years. It was assumed that by this time the majority of students that had taken the baseline exam in the freshman course would have completed the capstone course exam as well. Averages of the scores were compared for the classes as well as comparing individual student scores from the freshman to senior examinations.

\section{Study Results}

First it must be noted that the results presented here are only the averaged student scores from the NSPE Ethics Exam as administered in a 100-level CAD course and in the senior capstone course. Consequently it is difficult to make a complete determination of the effectiveness of the new professional ethics program from this limited data.

First a baseline of scores was established by taking the average scores from the two courses for the very first year of the program. That data is given in the table below.

Table 1, Baseline data for Comparison taken during first year of new ethics program

\begin{tabular}{|l|l|l|l|l|}
\hline Course & $\begin{array}{l}\text { NSPE Exam score } \\
\text { average }\end{array}$ & High Score & Low Score & $\begin{array}{l}\text { Standard } \\
\text { Deviation }\end{array}$ \\
\hline $\begin{array}{l}\text { 100-Level CAD } \\
\text { course first year } \\
\text { scores }\end{array}$ & $51.3 \%$ & 64 & 36 & 7.40 \\
\hline $\begin{array}{l}\text { Senior Capstone } \\
\text { first year scores }\end{array}$ & $59.3 \%$ & 96 & 48 & 18.66 \\
\hline
\end{tabular}

It can be seen that there is a very high score for the first-year of the exam in the capstone course. No other scores throughout the study period came anywhere near this value and so it is somewhat of an outlier. What caused this student to perform so much better on the exam than others is not known.

The next set of data presented is the average scores from the exams over the entire five-year period of the study. 
Table 2, Average NSPE Exam scores

\begin{tabular}{|l|l|l|l|l|}
\hline Course & $\begin{array}{l}\text { NSPE Exam 5- } \\
\text { year Average }\end{array}$ & High Score & Low Score & $\begin{array}{l}\text { Standard } \\
\text { Deviation }\end{array}$ \\
\hline $\begin{array}{l}\text { 100-Level CAD } \\
\text { students }\end{array}$ & $49.2 \%$ & 68 & 36 & 7.44 \\
\hline $\begin{array}{l}\text { Senior Capstone } \\
\text { students }\end{array}$ & $51.8 \%$ & 96 & 28 & 11.55 \\
\hline
\end{tabular}

Again, the single high score from the capstone course is not in-line with other student scores across the entire study. Looking at the two tables it can be seen that the average scores for the five-year period are lower than the scores from the baseline first-year data. High and low scores for the 100-level course do not significantly change. The low score from the capstone five-year average is measurably lower than the baseline from the first-year of the study.

In order to assess how well the new professional ethics instruction was having an effect on the students it would be necessary to see how the scores changed over the course of the next five years. The assumption was that the students that tested the first year of the program in the 100level CAD course would be the seniors in the capstone course in the next four or five years. The following table presents the average scores for the first-year of the exam for the CAD students compared with the fifth-year results for the capstone students.

Table 3, Comparison of Average student scores at the beginning and end of their education

\begin{tabular}{|l|l|l|l|l|}
\hline Course & $\begin{array}{l}\text { NSPE Exam score } \\
\text { average }\end{array}$ & High Score & Low Score & $\begin{array}{l}\text { Standard } \\
\text { Deviation }\end{array}$ \\
\hline $\begin{array}{l}\text { 100-Level CAD } \\
\text { course first year } \\
\text { scores }\end{array}$ & $51.3 \%$ & 64 & 36 & 7.40 \\
\hline $\begin{array}{l}\text { Senior Capstone } \\
\text { fifth year scores }\end{array}$ & $48.3 \%$ & 56 & 36 & 6.82 \\
\hline
\end{tabular}

It can be seen that regardless of when a student takes the assessment examination the scores seemed to stay fairly consistent around an average around 50\%. The fifth year scores for the capstone course were lower than both the initial baseline scores and the five-year average score. It should also be noted that no student ever scored $100 \%$ on the exam.

In order to try and better understand what might be the cause of this, results from individual students were tracked to see how their scores changed from their freshman exam to their one in senior capstone. The values in Table 4 show the average scores for select individual students 
who tested in the first-year of the program in the 100-level course and then tested in the senior capstone course five years later.

Table 4, Cohort scores of students progressing through the ethics program

\begin{tabular}{|l|l|l|l|l|}
\hline Course & $\begin{array}{l}\text { NSPE Exam score } \\
\text { average }\end{array}$ & High Score & Low Score & $\begin{array}{l}\text { Standard } \\
\text { Deviation }\end{array}$ \\
\hline $\left.\begin{array}{l}\text { Average of Exam } \\
\text { scores for } \\
\text { specifically } \\
\begin{array}{l}\text { identified students } \\
\text { in 100-Level } \\
\text { course }\end{array}\end{array}\right)$ & $56.0 \%$ & 48 & 5.66 \\
\hline $\begin{array}{l}\text { Average of those } \\
\text { same students from } \\
\text { their capstone } \\
\text { course }\end{array}$ & $51.0 \%$ & 56 & 44 & 4.36 \\
\hline
\end{tabular}

Again, the data shows scores that remain close to the $50 \%$ historical average with the average score $5 \%$ lower from the students when they were getting ready to graduate than when they were starting the program as freshmen.

\section{Conclusion}

Based purely on the percentage scores from the NSPE Ethics Exam two conclusions come to mind. Either student understanding of professional ethics has not measurably improved utilizing this new program or the NSPE exam was not functioning as an effective assessment tool. There are great limitations in the data that should be pointed out. First of all the data comes from a single 25-question exam given at two different times during a student's class experience in our MET program. It is difficult to determine how adequately this exam measures a student's understanding of professional ethics.

Another possible limitation to the data involves the large number of transfer students that attend our engineering technology program. These students generally come having already completed their CAD courses and so they did not contribute to the 100-level scores. They also would have missed out on going through the exam on this course and would be seeing the ethics exam for the first time in the capstone course. It is difficult to determine what, if any, effect this might have had on the data.

Another limitation to the data involves the very legalistic language involved in this particular examination and in professional ethics in general. As mentioned previously, when administering this examination to freshmen there is no discussion or answers provided to the exam. During the 
capstone administration the answers are provided along with a discussion about each question and the important ethics topic that the question is addressing. It can be observed from the discussion that once students understood the aspect of ethics being addressed by a particular topic then they were better able to understand the correct and incorrect responses to the question. Once particular example is the very first question on the exam. It reads as follows:

"1. Engineers, in the fulfillment of their professional duties, must carefully consider the safety, health, and welfare of the public."

Although percentages by specific exam questions were not calculated, it was pretty clear from those that graded the exams that this question was marked incorrectly by well over half of the students. It would appear that students focused on the word, "safety," and quickly marked the answer as "True." However, NSPE's answer code says this statement is false. It doesn't explicitly explain why but it makes a reference to section I.1 of its Code of Ethics ${ }^{1}$ which says:

"Engineers, in the fulfillment of their professional duties, shall: Hold paramount the safety, health, and welfare of the public."

It would seem that the thinking of those that created the test believe the first question is false because the words, "carefully consider," imply that the engineer is debating in his mind whether he wants to consider safety, health, and welfare before he makes a decision. If an engineer holds the safety, health, and welfare of the public as paramount then he doesn't need to "carefully consider" this. It is questions like this one that likely cause students with the correct way of thinking about professional ethics to still mark a test question incorrectly.

It also raised the question that students with limited experience working in a professional environment may not have the background to fully understand the different aspects of how ethics interacts with day-to-day work activities.

It is also suspected that asking instructors to include ethics topics in various courses with no specific framework likely had limited effect. Studies have shown that going about teaching ethics in this manner likely results in teaching "microethics"8 which lacks the broader context of how ethics impacts society as a whole.

It is also noted that senior engineering students that are taking their capstone course are very busy. The engineering capstone in our program is typical of other institutions in that it requires a large time commitment from the students. They have projects to complete, numerous reports to write, and presentations to prepare. It is likely that taking this ethics examination is not a high priority in their list of things to complete so it may not be given the serious attempt that we would hope from these students. Since the capstone course is taken as students are getting ready to graduate, many already have job offers and possibly may be undergoing a bit of "senior-itis". 
It is unfortunate that this study was not begun before the changes were implemented in order to provide a baseline of the effectiveness of the previous ethics education method. Therefore, any conclusions drawn from the study cannot relate back to the previous program and whether the changes had any beneficial or negative effects.

\section{For Future Study}

One aspect of this study that was not looked into was average scores on each of the 25 questions in the exam. Anecdotally, while grading the exams it was easy to discern that certain questions were more likely to be marked incorrectly and other ones were more likely to be marked correctly. It would be interesting to calculate percentages by question number in order to determine what it was about this exam that led to very consistent scores around $50 \%$ with little change in spite of our new program of professional ethics education.

It should be noted that although the scores on the examination were lower than hoped, the exam, as presented in the senior capstone course, provided a great source for some very animated discussion on professional ethics. So, from this standpoint there is some success from using the exam.

It was obvious that the results provided by the NSPE exam were not really useful to us as an assessment tool. The test itself is still used as a method to introduce professional ethics in our capstone course but it is not longer being used for assessment and data is no longer being kept on student scores. A better assessment method for professional ethics education is needed to replace this method.

Based on the results of this study along with challenges brought about by the addition of a new Mechanical Engineering program and enormous growth in enrollment, our department is once again revising its approach to how we teach professional ethics. What that new approach will be is still in the works. One change already implemented is the addition of a course to the curriculum on the topic of professional licensure. Students examine the purpose for professional licensure, the pathway to obtaining a license, and they review the topics that will be covered on the Fundamental of Engineering examination. Ethics is a topic on the FE exam and so students get additional exposure to this topic through this new course.

\section{Bibliography}

1. National Society for Professional Engineers (NSPE), "NSPE Code of Ethics for Engineers," (Accessed 2015). Available: http://www.nspe.org/resources/ethics.

2. Tau Beta Pi, The Engineering honor Society, "Code of Ethics of Engineers," (Accessed 2015). Available: http://www.tbp.org/about/InfoBook/ethics.cfm.

3. Barry B., and Yadav A. (2007). "The Case Method: Using Case-based Instruction to Increase Ethical 
Understanding in Engineering Courses." Purdue University. Department of Engineering Education. American Society for Engineering Education.

4. Dyrud, Marilyn A. (2004). "Cases for Teaching Engineering Ethics." Proceedings of the 34th ASEE/IEEE Frontiers in Education Conference. Retrieved from http://fie.engrng.pitt.edu//fie2004/papers/1161.pdf.

5. A. Dean Fontenot, Richard A. Burgess, (2012) "Professional Issues in Ethics Education" 2012 ASEE Annual Conference, San Antonio, TX

6. Accreditation Board for Engineering and Technology (ABET) (2007). Retrieved from http://www.abet.org/Linked\%20Documents-UPDATE/Criteria\%20and\%20PP/T001\%200708\%20TAC\%20Criteria\%2011-15-06-06.pdf

7. Durfee Jason, Loendorf William (2008) 'Using the national society of professional engineers' (NSPE) ethics examination as an assessment tool in the engineering technology curriculum”,2008 ASEE Annual Conference and Exposition, Pittsburg PA.

8. Herkert, Joseph R. (2005) "Ways of Thinking About and Teaching Ethical Problem Solving: Microethics and Macroethics in Engineering”, Science and Engineering Ethics, 11, 373-385.

\section{APPENDIX A: NSPE Ethics Examination}

NSPE's true/false exam tests your knowledge of professional engineering ethics. When you're done, click on the "Answers" link at the bottom of the page to see how well you did. This test is intended to test individual knowledge of the specific language contained in the NSPE Code of Ethics and is not intended to measure individual knowledge of engineering ethics or the ethics of individual engineers or engineering students.

\section{A series of true/false questions pertaining to the NSPE Code of Ethics follows.}

1. Engineers, in the fulfillment of their professional duties, must carefully consider the safety, health, and welfare of the public.

2. Engineers may perform services outside of their areas of competence as long as they inform their employers or clients.

3. Engineers may issue subjective and partial statements if such statements are in writing and consistent with the best interests of their employers, clients, or the public.

4. Engineers shall act for each employer or client as faithful agents or trustees.

5. Engineers shall not be required to engage in truthful acts when required to protect the public health, safety, and welfare.

6. Engineers may not be required to follow the provisions of state or federal law when such actions could endanger or compromise their employer or their clients' interests.

7. If engineers' judgment is overruled under circumstances that endanger life or property, they shall notify their employers or clients and such other authority as may be appropriate. 
8. Engineers may review but shall not approve those engineering documents that are in conformity with applicable standards.

9. Engineers shall not reveal facts, data...information without the prior consent of the client or employer except as authorized or required by law or this Code.

10. Engineers shall not permit the use of their names or associates in business ventures with any person or firm that they believe is engaged in fraudulent or dishonest enterprise, unless such enterprise or activity is deemed consistent with applicable state or federal law.

11. Engineers having knowledge of any alleged violation of this Code, following a period of 30 days during which the violation is not corrected, shall report thereon to appropriate professional bodies and, when relevant, also to public authorities, and cooperate with the proper authorities in furnishing such information or assistance as may be required.

12. Engineers shall undertake assignments only when qualified by education or experience in the specific technical fields involved.

13. Engineers shall not affix their signatures to plans or documents dealing with subject matter in which they lack competence, but may affix their signatures to plans or documents not prepared under their direction and control where they have a good faith belief that such plans or documents were competently prepared by another designated party.

14. Engineers may accept assignments and assume responsibility for coordination of an entire project and shall sign and seal the engineering documents for the entire project, including each technical segment of the plans and documents.

15. Engineers shall strive to be objective and truthful in professional reports, statements or testimony, with primary consideration for the best interests of the engineers' clients or employers. The engineers' reports shall include all relevant and pertinent information in such reports, statements, or testimony, which shall bear the date on which the engineers were retained by the clients to prepare the reports.

16. Engineers may express publicly technical opinions that are founded upon knowledge of the facts and competence in the subject matter.

17. Engineers shall not issue statements, criticisms, or arguments on technical matters that are inspired or paid for by interested parties, unless they have prefaced their comments by explicitly identifying the interested parties on whose behalf they are speaking and revealing the existence of any interest the engineers may have in the matters.

18. Engineers may not participate in any matter involving a conflict of interest if it could influence or appear to influence their judgment or the quality of their services. 
19. Engineers shall not accept compensation, financial or otherwise, from more than one party for services on the same project, or for services pertaining to the same project, unless the circumstances are fully disclosed and agreed to by all interested parties.

20. Engineers shall not solicit but may accept financial or other valuable consideration, directly or indirectly, from outside agents in connection with the work for which they are responsible, if such compensation is fully disclosed.

21. Engineers in public service as members, advisors, or employees of a governmental or quasigovernmental body or department may participate in decisions with respect to services solicited or provided by them or their organizations in private or public engineering practice as long as such decisions do not involve technical engineering matters for which they do not posses professional competence.

22. Engineers shall not solicit nor accept a contract from a governmental body on which a principal or officer of their organization serves as a member.

23. Engineers shall not intentionally falsify their qualifications nor actively permit written misrepresentation of their or their associate's qualifications. Engineers may accept credit for previous work performed where the work was performed during the period the engineers were employed by the previous employer. Brochures or other presentations incident to the solicitation of employment shall specifically indicate the work performed and the dates the engineers were employed by the firms.

24. Engineers shall not offer, give, solicit, nor receive, either directly or indirectly, any contribution to influence the award of a contract by a public authority, or which may be reasonably construed by the public as having the effect or intent of influencing the award of a contract unless such contribution is made in accordance with applicable federal or state election campaign finance laws and regulations.

25. Engineers shall acknowledge their errors after consulting with their employers or clients.

- See more at: http://www.nspe.org/resources/ethics/ethics-resources/code-ethicsexamination\#sthash.fzVaPlde.dpuf 